\title{
Argulus chicomendesi sp. n. (CRUSTACEA: ARGULIDAE) PARASITA DE PEIXES DA AMAZÔNIA BRASILEIRA.
}

\author{
José Celso de Oliveira MALTA*, Angela Maria Bezerra VARELLA*
}

\begin{abstract}
RESUMO - Uma nova espécie de Branchiura é descrita para o Brasil. Os espécimens foram coletados parasitando peixes da Amazônia brasileira. A nova espécie é caracterizada pela: coloração e desenhos da superfície dorsal da carapaça, tórax e abdômen; presença de espinhos em toda a margem externa da superficie ventral do abdômen (pléon); ornamentações das antenas, antênulas, maxilas, pernas, superfície ventral do corpo; forma e pigmentação das estruturas copulatórias acessórias do macho.
\end{abstract}

Palavras chaves: Branchiura; Parasita de peixes de água doce; rios Amazonas/Solimões; Aquacultura.

Argulus chicomendesi sp. n. (Crustacea: Argulidae) Parasite of Fishes from Brazilian Amazon.

ABSTRACT - A new species of Branchiura is described from Brazil. The specimens were collected from the fishes of the Brazil Amazon. The new species is characterised by: coloration; form and design of dorsal surface carapace, thorax and abdomen; spines in all external margin and ventral surface of abdomen (pleon); ornamentations of the antennae, antennules, legs, ventral surface of the body; form and pigmentation of accessory copulatory structures from the male.

Key-words: Branchiura; Parasites of freshwater fishes; Amazonas/Solimões rivers; Aquaculture.

\section{INTRODUÇÃO}

A subclasse Branchiura é formada pela ordem Argulidea, que possui duas famílias: Argulidae e Dipteropeltidae. A Argulidae têm três gêneros: Argulus Müller, 1785; Dolops Audouin, 1837 e Chonopeltis Thiele, 1901. A Dipteropeltidae um, Dipteropeltis Calman, 1912 (Bouvier, 1899; Wilson, 1902; Calman, 1912; Yamaguti, 1963). Vivem na superfície do corpo, bases das nadadeiras, cavidades bucal e branquial de peixes, ocasionalmente de anfibios e répteis. Causam uma série de danos a seus hospedeiros, através de ações espoliadoras e traumatização de tecidos com seus órgãos de fixação. Quando parasitam a cavidade bucal e branquial diminuem a capacidade respiratória, com a retirada de sangue, destruição dos tecidos, interrupção da circulação sangüinea, oclusão dos vasos aferentes, formação de coágulos e hipertrofia dos filamentos, freqüentemente causam sérios prejuízos em cultivos de peixes (Ringuelet, 1943; Lemos de Castro, 1950; Kabata, 1970, 1985; Malta, $1981 ; 1982 \mathrm{a} ; 1982 \mathrm{~b} ; 1983 ; 1984$; Malta \& Varella, 1983).

Cerca de 150 espécies de Branchiura são conhecidas, 110 do gênero Argulus. São cosmopolitas e ocorrem tanto em água doce quanto

\footnotetext{
* Laboratório de Parasitologia de Peixes (L.PP); Coordenação de Pesquisas em Biologia Aquática (CPBA), Instituto Nacional de Pesquisas da Amazônia (INPA), Caixa Postal 478, Manaus, Amazonas, Brasil, CEP 69011-970. tel . 550926433144 FAX 6433240.
} 
salgada, sendo 18 endêmicas à região Neotropical. Dez espécies de Dolops são endêmicas à região Neotropical exceto uma, que ocorre na região Etiópica. Seis espécies de Chonopeltis são endêmicas à região Etiópica. Uma espécie de Dipteropeltis é endêmica à região Neotropical (Calman, 1912a; 1912b; Ringuelet, 1943; Malta, 1981; 1982a). Para o Brasil são citadas nove espécies do gênero Argulus, nove de Dolops e uma de Dipteropeltis (Malta, 1998).

Os branquiúros não carregam seus ovos em sacos, como os Copepoda, os depositam em substratos sólidos: pedras, troncos, paredes de aquários e tanques, são eximios nadadores podendo sobreviver por muitos dias sem o hospedeiro. Durante a época de reprodução ambos os sexos abandonam o hospedeiro e saem a procura de um local para postura (Wilson, 1902; Ringuelet, 1943).

Das 21 espécies de Branchiura que ocorrem na região Neotropical, dez foram registradas na região Amazônica: quatro de Argulus, cinco de Dolops e uma de Dipteropeltis. Apresentaram uma sazonalidade de ocorrência com os maiores índices de infestação na estação de cheia e os menores na seca. Cerca de 30 espécies de peixes foram registradas como hospedeiras naturais de Branchiura. Algumas espécies apresentaram especificidade parasitária: A. pestifer só ocorreu em peixes do gênero Pseudoplatystoma; D. striata só ocorreu em três espécies de dois gêneros da família Anostomidae. Entre os grandes grupos de peixe os
Siluriformes foram os que apresentaram a maior pressão parasitária por Branchiura, seguidos pelos Characiformes e Perciformes. Quanto ao hábito alimentar dos hospedeiros, os herbivoros foram os que apresentaram os maiores índices de infestação, seguidos pelos carnivoros e finalmente os detritívoros (Malta, 1981; 1982a; 1982b, 1983; Malta \& Varella, 1983; Malta \& Santos-Silva, 1986).

Apesar da importância dos branquiúros como patógenos, estas espécies são pouco conhecidas e não são facilmente identificadas (Kabata, 1985). Existem descrições que são obscuras, causando dificuldades na identificação e várias espécies foram descritas mais de uma vez (RushtonMellor, 1994a; 1994b; 1994c). Apesar do gênero Argulus ter mais de 120 espécies, ser marinho e de água doce e ter distribuição cosmopolita. Desafortunadamente, mesmo exames superficiais revelam que o grupo contém muitas espécies nominais com o estatus taxonômico questionável (Benz et al., 1995).

\section{MATERIAL E MÉTODOS}

Os peixes foram coletados no lago Janauacá situado acerca de $70 \mathrm{~km}$ de Manaus, Estado do Amazonas, na margem direita do rio Solimões entre as coordenadas geográficas $3^{\circ} 25^{\prime} \mathrm{S}$ e $60^{\circ} 13^{\prime} \mathrm{W}$, no rio Negro próximo à Manaus e no rio Guaporé próximo à Pimenteiras. Os aparelhos de pesca utilizados nas capturas foram malhadeiras, redinhas e linha de mão. Também foram coletados nas estações 
de Aquacultura do INPA e a da estrada AM-010, Manaus-Itacoatiara no Estado do Amazonas. Os peixes foram coletados, examinados e devolvidos aos tanques. Um lote de peixes foi comprado na segunda estação, transportados para o laboratório de parasitologia do INPA, em Manaus e mantidos em tanques de cimento amianto de 1000 litros.

Todos os peixes foram examinados cuidadosamente: na superfície externa do corpo; base das nadadeiras; cavidades branquial e bucal. Posteriormente, foram numerados, identificados, pesados e medidos (comprimento padrão).

Os branquiúros foram retirados dos peixes utilizando finas pinças e pincéis e transferidos para formol $5 \%$ tamponado com bórax ou álcool $70 \%$. Lâminas permanentes, com montagem total foram preparadas usando o método de fenol, orange $\mathrm{G}$ (publicado em Monoculus n.15 de novembro de 1987). Lâminas escavadas com glicerina e álcool $70 \%$ foram utilizadas para montagens provisórias com crustáceos inteiros, dissecados e diafanizados em hipoclorito de sódio $5 \%$.

Os desenhos foram feitos com o auxílio de câmara clara. As medidas foram obtidas com uma ocular micrométrica e expressas em milimetros, são dadas as amplitudes minimas, máximas e a média entre parênteses. Os peixes foram depositados na Coleção Ictiológica do Instituto Nacional de Pesquisas da Amazônia, em Manaus. Os tipos foram depositados na Coleção de
Invertebrados do Instituto Nacional de Pesquisas da Amazônia (INPA-CR), Manaus, Amazonas, Brasil e Museu de Zoologia da Universidade de São Paulo (MZUSP), São Paulo, Brasil.

\section{Material examinado}

Argulus chicomendesi sp. n. (Figs. 1 - 17)

Holótipo: fêmea (INPA-CR 677), da superfície do corpo de Colossoma macropomum (Cuvier, 1818) capturado no lago Janauacá, entre as coordenadas geográficas $3^{\circ}$ $25^{\prime} \mathrm{S}$ e $60^{\circ} 13^{\prime} \mathrm{W}$, margem direita do rio Solimões (Amazonas), Estado do Amazonas, Brasil, 27-ix-1979, em meio liquido. Parátipos: 50 fêmeas e 33 machos em meio líquido; uma fêmea de Prochilodus nigricans (Agassiz, 1829) da localidade-tipo, J.C. Malta, 21/i/1980, (INPA-CR 678); uma fêmea e um macho de Pseudoplatystoma tigrinum (Valenciennes, 1840) (da localidadetipo J.C. Malta, 14/ix/1979, (INPA-CR 679); dois machos de Hipophtalmus edentatus Spix, 1829 da localidadetipo J.C. Malta, 14/ix/1979, (INPA-CR 680); três fêmeas de Pygocentrus nattereri (Kner, 1860), da localidadetipo, J.C. Malta, 23/i/1980, (INPA-CR 681); quatro fêmeas de Schizodon fasciatus Agassiz, 1829 da localidadetipo, J.C. Malta, 23/i/1980, (INPA-CR 685); duas fêmeas e um macho de Brycon erythropterum (Cope, 1872) rio Negro, AM, A. Varella, 30/ix/1982, (INPA-CR 764); treze fêmeas e seis machos de Brycon erythropterum, Estação de Aquacultura do INPA, AM, J.C. Malta, 14/vi/1983 (INPA-CR 


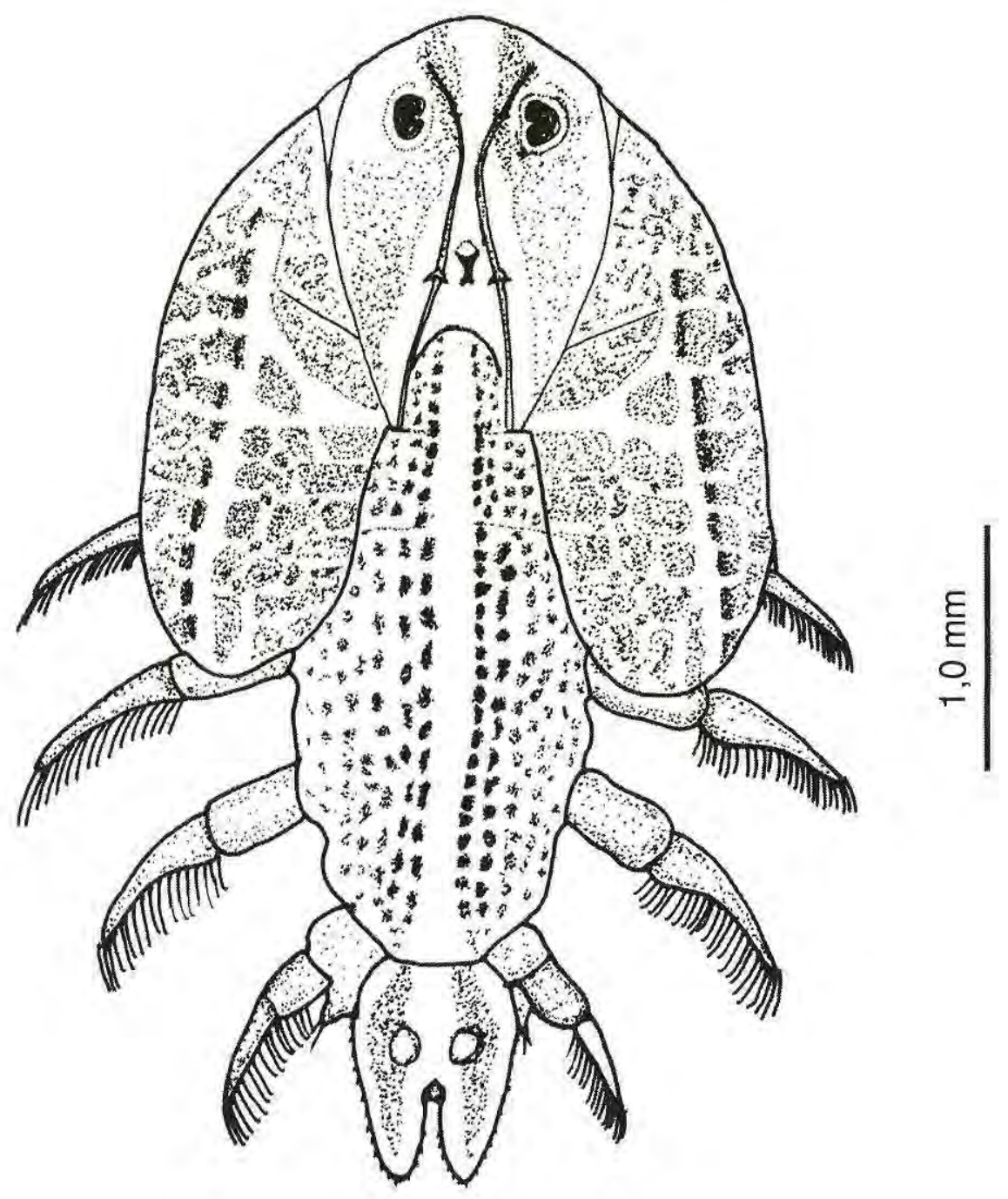

Figura 1. Argulus chicomendesi sp. n., fềmea, corpo em vista dorsal. 
765); duas fêmeas de Schizodon fasciatus (Agassiz, 1829) do rio Guaporé, Pimenteiras, RO, J.C. Malta, 28/xi/1984 (INPA-CR 766); quatro fêmeas e sete machos de Colossoma macropomum da estação de Aquacultura de Itacoatiara, AM, C. Fischer, 12/x/1997 (INPA-CR 767); oito fêmeas e nove machos de Colossoma macropomum da estação de Aquacultura de Itacoatiara, A.L. Gomes, 07/i/1998 (INPA-CR 768). Seis fêmeas e três machos em lâminas de Brycon erythropterum, Estação de Aquacultura do INPA, AM, J.C. Malta, 14/VI/1983 (INPA-CR 769).
Fêmea(Figs. 1 - 12 e Tab. 1), $\mathrm{n}=10$

Comprimento total dos exemplares examinados (ct) 4,1 - 6,4 $(4,8) \mathrm{mm}$ (Fig. 1) (Tab. 1). Superfície dorsal de cor levemente esbranquiçada com desenhos formados por pontos de pigmentos castanhos. Carapaça em forma de coração, mais larga que longa. Comprimento da carapaça (cc) $2,6-2,9(2,8) \mathrm{mm}$ (Tab. 1). Relação comprimento total/comprimento da carapaça (ct/cc) $1,5-2,3(1,7)$. Lobos laterais da carapaça cobrem os simpóditos e um terço dos endopóditos e exopóditos do primeiro

Tabela 1. Medidas em milímetros de dez fêmeas de Argulus chicomendesi sp. n. (em negrito amplitudes mínimas, máximas e as médias)

M. V. D.P

\begin{tabular}{|c|c|c|c|c|c|c|c|c|c|c|c|c|c|}
\hline Exemplares medidos & 1 & 2 & 3 & 4 & 5 & 6 & 7 & 8 & 9 & 10 & & & \\
\hline Comprimento total (ct) & 6,4 & 5,0 & 4,5 & 4,4 & 4,1 & 4,4 & 4,2 & 4,8 & 4,5 & 5,2 & 4,8 & 0,45 & 0,67 \\
\hline Comprim. carapaça $(\propto)$ & 2,8 & 2,8 & 2,9 & 2,7 & 2,7 & 2,8 & 2,6 & 2,9 & 2,9 & 2,8 & 2,8 & 0,01 & 0,07 \\
\hline Comprim. abdôm. (ca) & 0,8 & 0,9 & 0,9 & 0,9 & 0,7 & 0,8 & 1,0 & 0,8 & 0,8 & 0,7 & 0,8 & 0,01 & 0,09 \\
\hline Largura carapaça (Ic) & 2,8 & 2,7 & 2,4 & 2,2 & 2,2 & 2,6 & 2,4 & 2,3 & 2,7 & 2,0 & 2,4 & 0,07 & 0,26 \\
\hline Largura abdômen (la) & 0,6 & 0,6 & 0,8 & 0,7 & 0,6 & 0,8 & 0,6 & 0,6 & 0,7 & 0,6 & 0,7 & 0,01 & 0,08 \\
\hline $\mathrm{cc} / \mathrm{c}$ & 1,0 & 1,0 & 1,2 & 1,2 & 1,2 & 1,1 & 1,1 & 1,3 & 1,1 & 1,4 & 1,2 & 0,02 & 0,12 \\
\hline $\mathrm{ct} / \mathrm{ca}$ & 8,0 & 5,6 & 5,0 & 4,9 & 5,9 & 5,5 & 4,2 & 6,0 & 5,6 & 7,4 & 6,0 & 1,31 & 1,14 \\
\hline $\mathrm{caAa}$ & 1,3 & 1,5 & 1,1 & 1,3 & 1,2 & 1,0 & 1,7 & 1,3 & 1,1 & 1,2 & 1,3 & 0,04 & 0,20 \\
\hline $\mathrm{CC} / \mathrm{CA}$ & 3,5 & 3,1 & 3,2 & 3,0 & 3,9 & 3,5 & 2,6 & 3,6 & 3,6 & 4,0 & 3,4 & 0,18 & 0,42 \\
\hline $\mathrm{CT} / \mathrm{CC}$ & 2,3 & 1,8 & 1,6 & 1,6 & 1,5 & 1,6 & 1,6 & 1,7 & 1,6 & 1,9 & 1,7 & 0,05 & 0,23 \\
\hline
\end{tabular}

( $\mathrm{M}=$ média; $\mathrm{V}=$ variança; D.P.=desvio padrão) 
par de pernas (pereiópodo, toracópodo) e a metade anterior dos simpóditos do segundo par.

Região frontal (cefálica; cefalotórax) (Figs. 1 e 2) suavemente proeminente e bem delimitada pelos sulcos (depressões) ântero-laterais e pelo sulco cefálico posterior (Fig. 1). Sulcos ântero-laterais com um suave sulco lateral secundário no terço posterior (Fig. 1). Costelas inter-ocularis bem definidas, terço distal com uma pequeníssima prolongação lateral em ambos os lados. Olhos compostos grandes, bem definidos, completamente evidentes, localizados na mesma altura da junção entre a região frontal e a porção principal da carapaça (Fig. 1). Olho de náuplio claramente visível na linha mediana do corpo, um pouco à frente das prolongações laterais das costelas inter-ocularis (Fig. 1). Superficie ventral da região frontal da carapaça, ornamentada com pequenos espinhos direcionados posteriormente, somente na área triangular entre as duas antenas (Fig. 2).

Lobos laterais da carapaça (alae; asas, áreas posterolaterais) (Figs. 1 e 2) bem definidos e arredondados, separados por largo sinus (seio posterior do pléon) que alcança um pouco mais da metade da carapaça. Desenhos dorsais (Fig. 1) formados por pontos de pigmentos castanhos definindo uma faixa principal paralela às margens dos lobos; bifurca-se na altura das inserções posteriores das costelas interoculares e volta a se encontrar. Há uma série secundária intrincada de pequenas faixas interligadas (Fig. 1). Relação comprimento da carapaça/ largura da carapaça (cc/lc) 1,0 - 1,4 $(1,2)$. Áreas respiratórias (Figs. 2 e 3 ) suavemente definidas na superfície ventral dos lobos, ocupando cerca de $80 \%$ da área dos lobos, pouco evidentes. A anterior é menor, triangular, sendo 5,5 vezes menor ( $18 \%$ da maior). A posterior com um estrangulamento na margem mediana

Tórax (péreon) (Figs. 1 e 2), longo, grosso, bem definido, com quatro somitos não individualizados, sem uma forma definida devido a grande massa de óvulos em seu interior. Desenhos formados por pontos de pigmentos castanhos em toda superfície dorsal do péreon, exceto na faixa mediana que é despigmentada (Fig. 1). Esta faixa longitudinal é bem definida e visível, tem cerca de um quarto da largura do péreon. Começa no sulco cefálico posterior e termina na margem posterior do último somito do péreon (Fig. 1).

Abdômen (pléon) (Figs. 1 e 2), curto, de forma sub-retangular com margens arredondadas, ligeiramente mais longo do que largo. Relação comprimento total/comprimento do abdômen (ct/ca ) 4,2-8,0 (6,0). Comprimento do abdômen (ca) variando de $0,7-1,0(0,8)$, largura do abdômen (la) 0,6 - 0,8 (0,7) (Tab. 1). Relação comprimento do abdômen/ largura do abdômen (ca/la) de 1,0 - 1,7 $(1,3)$ (Tab. 1). Par de espermatecas, localizadas quase na região mediana, bem visíveis e arredondadas (Figs. 1 e 2). Lobos afinando posteriormente ao seio anal, com forma suavemente arredondada nas pontas (Figs. 1 e 2). Superfície ventral ornada com espinhos (Fig. 2). Toda margem 


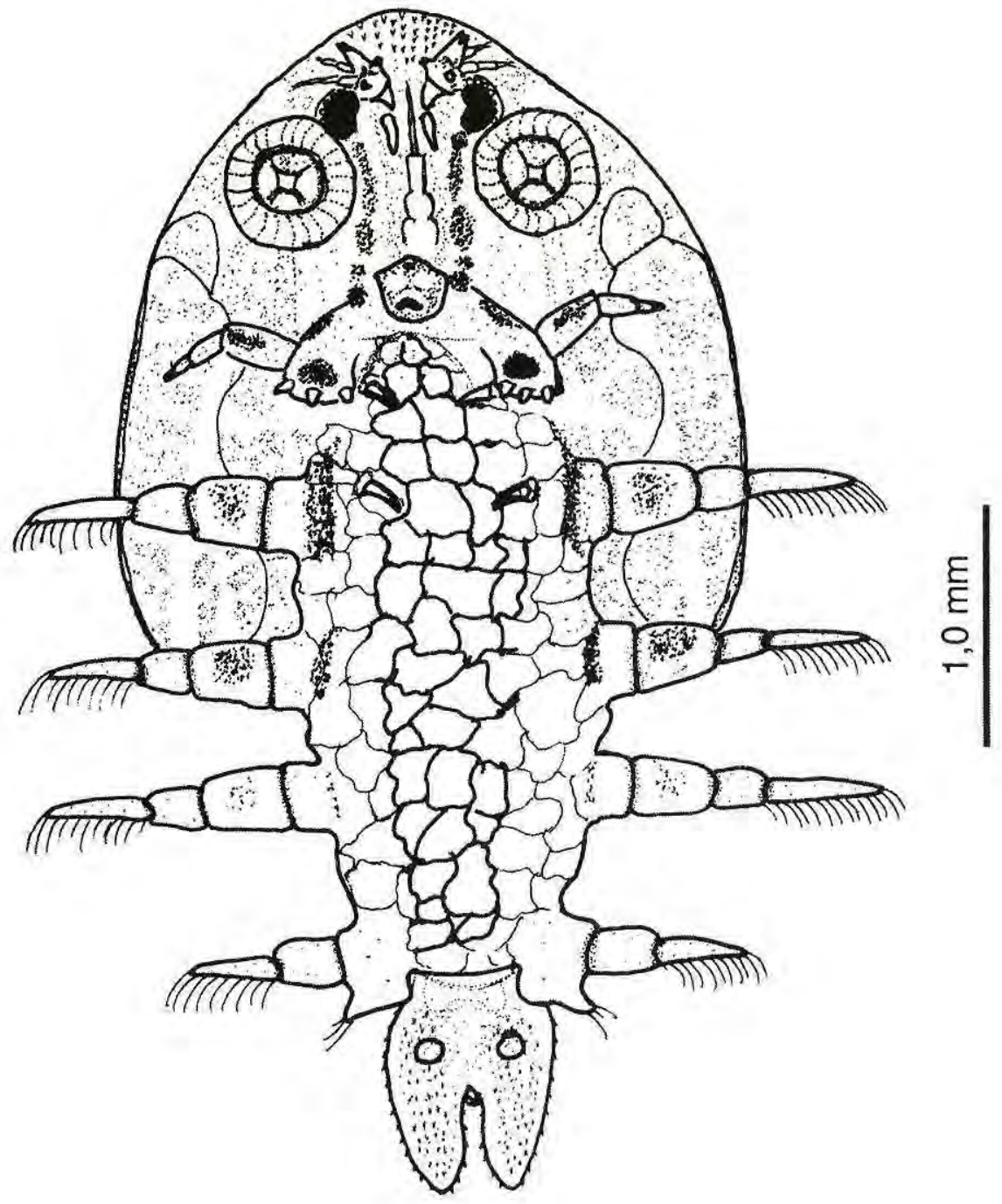

Figura 2. Argulus chicomendesi sp. n., fêmea, corpo em vista ventral. 
externa do pléon ornada com uma fileira de pequenos espinhos (Figs. 1 e 2). Seio posterior do pléon (sinus) bem definido, com cerca de metade do comprimento total do abdômen (Figs. 1 e 2). Ramos caudais pequenos, situados próximos à base dos lobos abdominais (Fig. 4). Duas faixas paralelas formadas por tênues pigmentos castanhos em toda extensão do pléon.

Antênulas (primeiro par de antenas) (Fig. 5) com quatro segmentos, os dois primeiros fortemente esclerotizados e ornados com espinho e ganchos; os dois últimos suavemente esclerotizados e ornados com setas. Primeiro segmento de forma triangular, posteriormente em forma de um espinho grosso (espinho posterior interno), ligeiramente curvado para o lado externo. Segundo segmento, o maior, com um forte gancho lateral, voltado pósteroventralmente; um forte espinho posterior externo de forma romboidal, no terço ântero distal e um forte gancho anterior, voltado posteroventralmente. Terceiro segmento liso. Quarto segmento, com cerca de um quarto do comprimento do anterior e com três setas apicais.

Antenas (segundo par de antenas) (Fig. 5) com quatro segmentos. Primeiro segmento o mais robustos e esclerotizado com um espinho romboidal. Demais segmentos tubulares decrescendo suavemente de tamanho. Segundo e terceiro segmentos com uma seta e o quarto com três (Fig. 5). Um par de espinhos mesiais (espinhos pós-antenais) um de cada lado do corpo, voltados ligeiramente para o lado externo, localizados próximos e posteriores à base da projeção basal da antena.

Maxílulas (primeiras maxilas) (Fig. 2) formando fortes ventosas. Hastes (costelas; raios) quitinosas de sustentação (Fig. 6) das ventosas com seis segmentos, o basal de forma subtriangular e o mais longo, os demais de forma romboidal decrescendo suavemente de tamanho (Fig. 6). Periferia da ventosa com uma fina membrana. Estilete bucal (estilete préoral; espinho préoral; ferrão; agulha) e bainha, visíveis entre as ventosas, cone bucal (probóscide; tubo bucal), sem ornamentação ou armadura (Fig. 2). Mandíbulas dentíferas parcialmente visíveis no cone bucal.

Maxilas (segundas maxilas) (Fig. 2) formadas por cinco segmentos. Primeiro segmento (basal; placa basal) de forma triangular, margem posterior com três dentes maxilares semelhantes (espinhos romboidais). Área acima dos dentes, com pigmentação determinando uma região triangular distal, próximo ao vértice anterior, área despigmentada formando um círculo. Segundo segmento alongado, robusto, afina suavemente em direção distal, a partir da região média posterior, ornado com escamas pectinadas (espinhos cuspidados), pontas voltadas posteriormente. Terceiro e quarto segmentos com cerca da metade do comprimento do anterior, com forma retangular, ornamentados com escamas pectinadas (espinhos cuspidados), pontas voltadas lateralmente. Quinto segmento (apical) 
o menor, ornamentado com um gancho, uma garra e uma projeção em forma de clava (Figs. 7 e 8). Primeiro par de espinhos pós-maxilares na mesma altura dos dentes maxilares, segundo na altura do primeiro par de pernas e ambos, voltados para parte interna (Fig. 2).

Primeiro ao quarto pares de pernas (pernas natatórias, pernas torácicas, toracópodos, pereópodos)
(Figs. 9 - 12) birremes, simpóditos (coxopódito e basipódito) com dois segmentos endopóditos e exopóditos ornados com setas plumosas. Primeiro e segundo pares de pernas (Figs. $9 \mathrm{e}$ 10) com um flagelo dorsal no segundo segmento ornado com setas plumosas: uma apical; duas setas pequenas laterais e seis na margem posterior do primeiro par e sete no
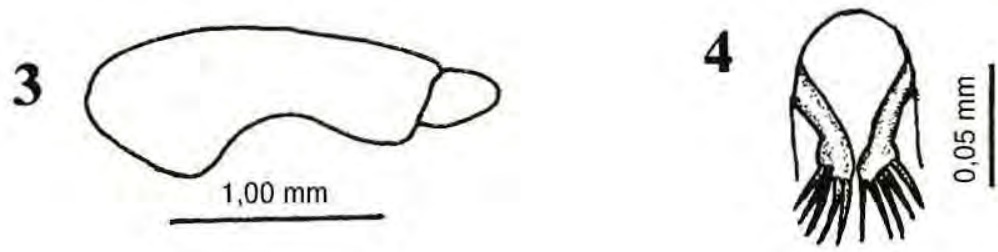

6
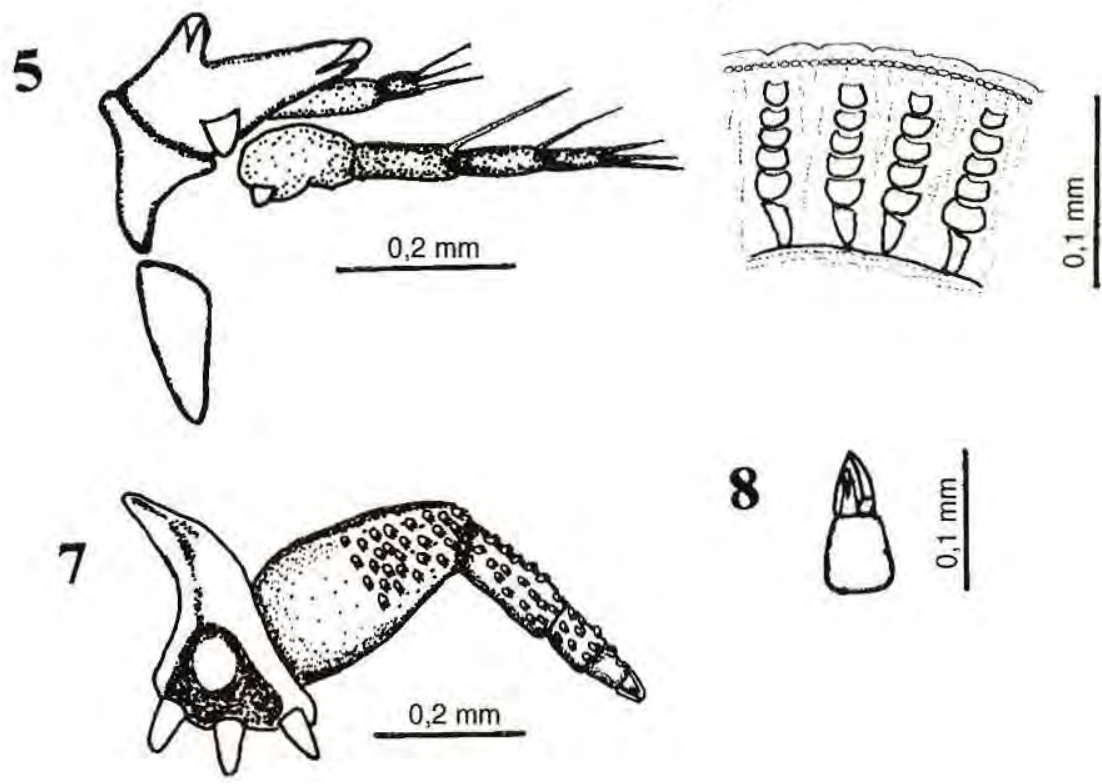

Figuras 3-8. Argulus chicomendesi sp. n. 3 - áreas respiratórias; 4 - ramos caudais; 5 - antenas.; 6 - hastes quitinosas; 7 - maxila; 8 - detalhe do segmento distal da maxila. 
segundo. Primeiro par de pernas (Fig. 9): primeiro segmento com espinhos e duas pequenas setas plumosas na margem média posterior; segundo segmento e endopódito com espinhos multicuspidados (escamas). Segundo e terceiro pares de pernas com uma fileira de pequenos espinhos na margem anterior do exopódito e espinhos no primeiro e segundo segmentos e metade anterior do endopódito (Figs. 10 - 11). Quarto par de pernas (Fig. 12): primeiro e segundo segmentos com espinhos; primeiro segmento com o lobo natatório (expansão do coxopódito) evidente, com margens arredondadas e extremidade posterior afilando posteriormente e ornado com sete setas plumosas; segundo segmento com quatro setas plumosas na margem posterior e metade anterior do endopódito com espinhos.

\section{Macho(Figs. 13 - 17 e Tab. 2), $\mathrm{n}=9$}

Comprimento total dos exemplares examinados (ct) 3,1 $3,5(3,1) \mathrm{mm}$, sendo $55-76(65 \%)$ menor que a fềmea (Fig. 13 e Tab. 2). Superfície dorsal de cor levemente esbranquiçada com desenhos formados por pontos de pigmentos castanhos, mas com coloração mais suave e densa que nas fêmeas. Carapaça em forma de coração, ligeiramente mais larga que longa. Comprimento da carapaça(cc) 1,4 $1,8(1,7) \mathrm{mm}$ (Tab. 2). Relação comprimento total/comprimento da carapaça (ct/cc) 1,6 - 2,3 (1,9).

Região frontal (cefálica; cefalotórax) (Fig. 13) mais definida que na fêmea e bem delimitada pelos sulcos (depressões) ântero-laterais e pelo sulco cefálico posterior. Lobos laterais da carapaça (alae; asas, áreas posterolaterais) (Fig. 13) bem definidos arredondados; separados por largo e curto sinus (seio posterior do pléon) que mede cerca de $20 \%$ do comprimento da carapaça. Muito mais curtos que os da fêmea, cobrem a metade anterior dos simpóditos do primeiro par de pernas (pereópodo, toracópodo) e o terço anterior dos simpóditos do segundo par. Desenhos dorsais da carapaça formados por pontos de pigmentos castanhos, semelhantes aos da fêmea, mas menos densos. Áreas respiratórias (Fig. 13) suavemente definidas e podendo ser vistas, parcialmente, na superfície dorsal dos lobos, nas fêmeas só são visíveis ventralmente.

Tórax (péreon) (Fig. 13) menor, mais estreito e menos proeminente que o da fêmea. Formado por quatro somitos bem definidos e individualizados. Sem desenhos definidos, mas com pigmentos castanhos pouco densos em toda extensão, exceto em alguns pontos, ao longo da linha mediana, onde concentram-se formando manchas escuras. Faixa longitudinal mediana do péreon com pouca definição e pouco visível.

Abdômen (pléon) (Fig. 13) de forma oval e ligeiramente mais 
9
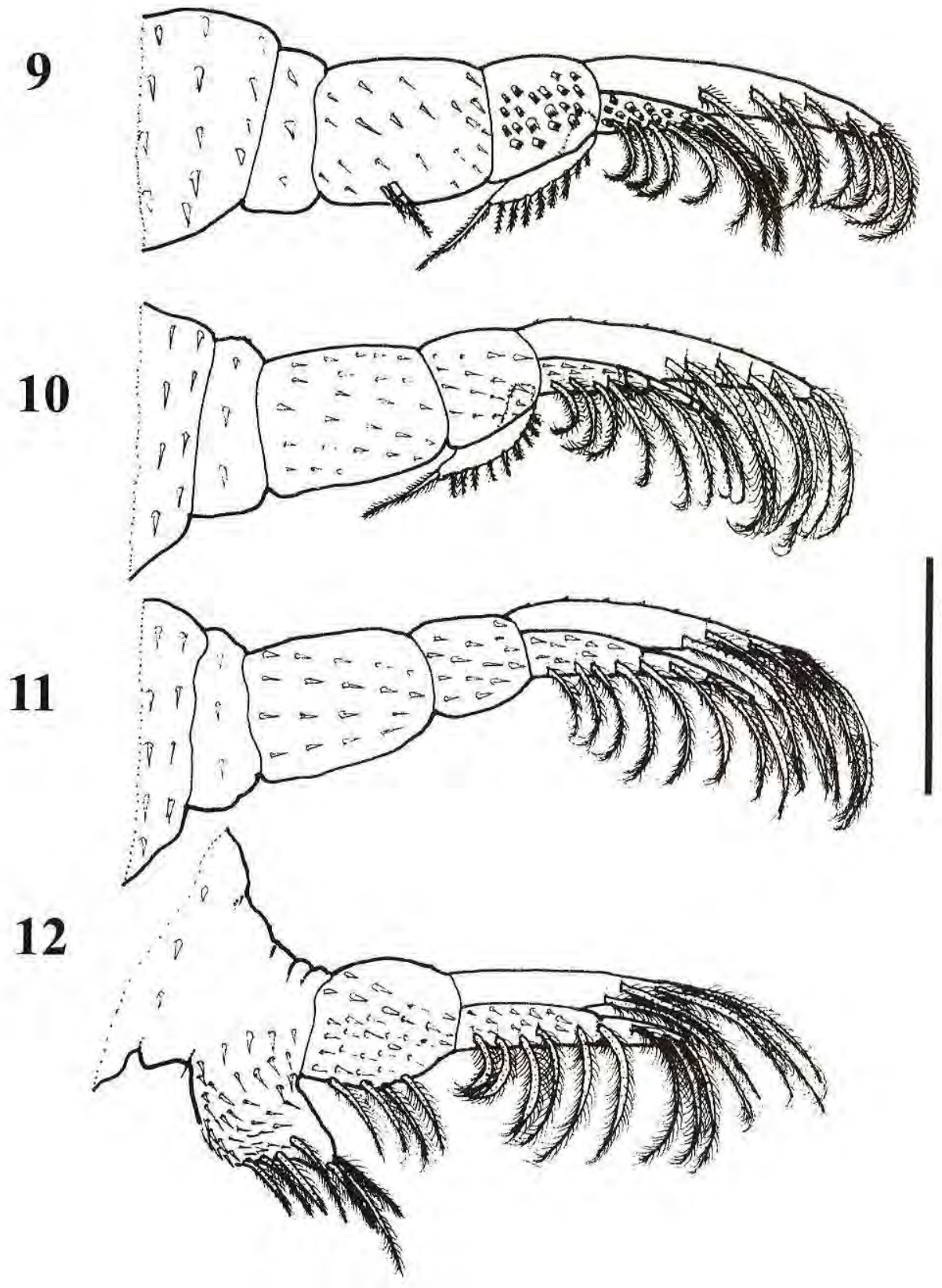

Figuras 9 - 12. Argulus chicomendesi sp. n., fềmea (vista dorsal): 9 - perna $1 ; 10$ - perna 2; 11 - perna $3 ; 0,1 \mathrm{~mm}$ - perna 4. 
Tabela 2. Medidas em milímetros de dez machos de Argulus chicomendesi sp. n. (em negrito amplitudes mínimas, máximas e as médias)

\begin{tabular}{|c|c|c|c|c|c|c|c|c|c|c|c|c|}
\hline & & & & & & & & & & M & v & D.P. \\
\hline Exemplares medidos & 1 & 2 & 3 & 4 & 5 & 6 & 7 & 8 & 9 & & & \\
\hline Comprimento total (CT) & 3,1 & 3,3 & 3,1 & 3,1 & 3,5 & 3,1 & 3,2 & 3,1 & 2,7 & 3,1 & 0,04 & 0,21 \\
\hline Comprim. carapaça(CC) & 1,5 & 1,6 & 1,8 & 1,7 & 2,0 & 2,0 & 1,4 & 1,5 & 1,5 & 1,7 & 0,05 & 0,22 \\
\hline Comprim. abdôm. (CA) & 0,8 & 0,9 & 0,7 & 0,8 & 0,8 & 0,8 & 0,9 & 0,8 & 0,8 & 0,8 & 0,00 & 0,06 \\
\hline Largura carapaça (LC) & 1,3 & 1,4 & 1,6 & 1,3 & 1,8 & 1,6 & 1,5 & 1,3 & 1,1 & 1,4 & 0,05 & 0,21 \\
\hline Largura abdômen (LA) & 0,5 & 0,5 & 0,5 & 0,4 & 0,7 & 0,4 & 0,5 & 0,4 & 0,4 & 0,5 & 0,01 & 0,10 \\
\hline CC/LC & 1,2 & 1,2 & 1,2 & 1,3 & 1,1 & 1,3 & 0,9 & 1,2 & 1,4 & 1,2 & 0,02 & 0,12 \\
\hline $\mathrm{CT} / \mathrm{CA}$ & 3,9 & 3,9 & 3,9 & 3,9 & 4,4 & 3,9 & 3,6 & 3,9 & 3,4 & 3,8 & 0,07 & 0,27 \\
\hline CA/LA & 1,6 & 1,6 & 1,6 & 2,0 & 1,1 & 2,0 & 1,8 & 2,0 & 2,0 & 1.7 & 0,09 & 0,29 \\
\hline
\end{tabular}

( $M=$ média; V=variança; $D . P .=$ desvio padrão)

comprido que largo. Relação comprimento total/comprimento do abdômen (ct/ca) 3,4 - 4,4 (3,8) (Tab. 2). Largura do abdômen (la) 0,4 - 0,7 $(0,5)$ (Tab. 2). Relação comprimento do abdômen/largura do abdômen (ca/ 1a) 1,1 - 2,0 (1,7) (Tab. 2). Par de testículos pouco definido, do mesmo formato que o abdômen, ocupando cerca de $90 \%$ da área abdominal. Lobos afinando posteriormente ao seio anal, com forma lanceolada nas extremidades. Seio posterior do pléon bem definido, com cerca de $42 \%$ do comprimento total do abdômen. De cada lado da linha mediana do pléon há uma série de concentração de pigmentos, formando manchas escuras em toda extensão. Maxílulas (primeiras maxilas) suavemente visiveis em vista dorsal nos machos.

Primeiro ao quarto pares de pernas (pernas natatórias, pernas torácicas, toracópodos, pereópodos) (Figs. 13 - 17) birremes, simpóditos (coxopódito e basipódito) com dois segmentos endo e exopóditos ornados com setas plumosas. Primeiro e segundo pares de pernas (Figs. 14 15) com um flagelo dorsal no segundo segmento, ornado com setas plumosas, uma apical e cinco laterais, a mais 


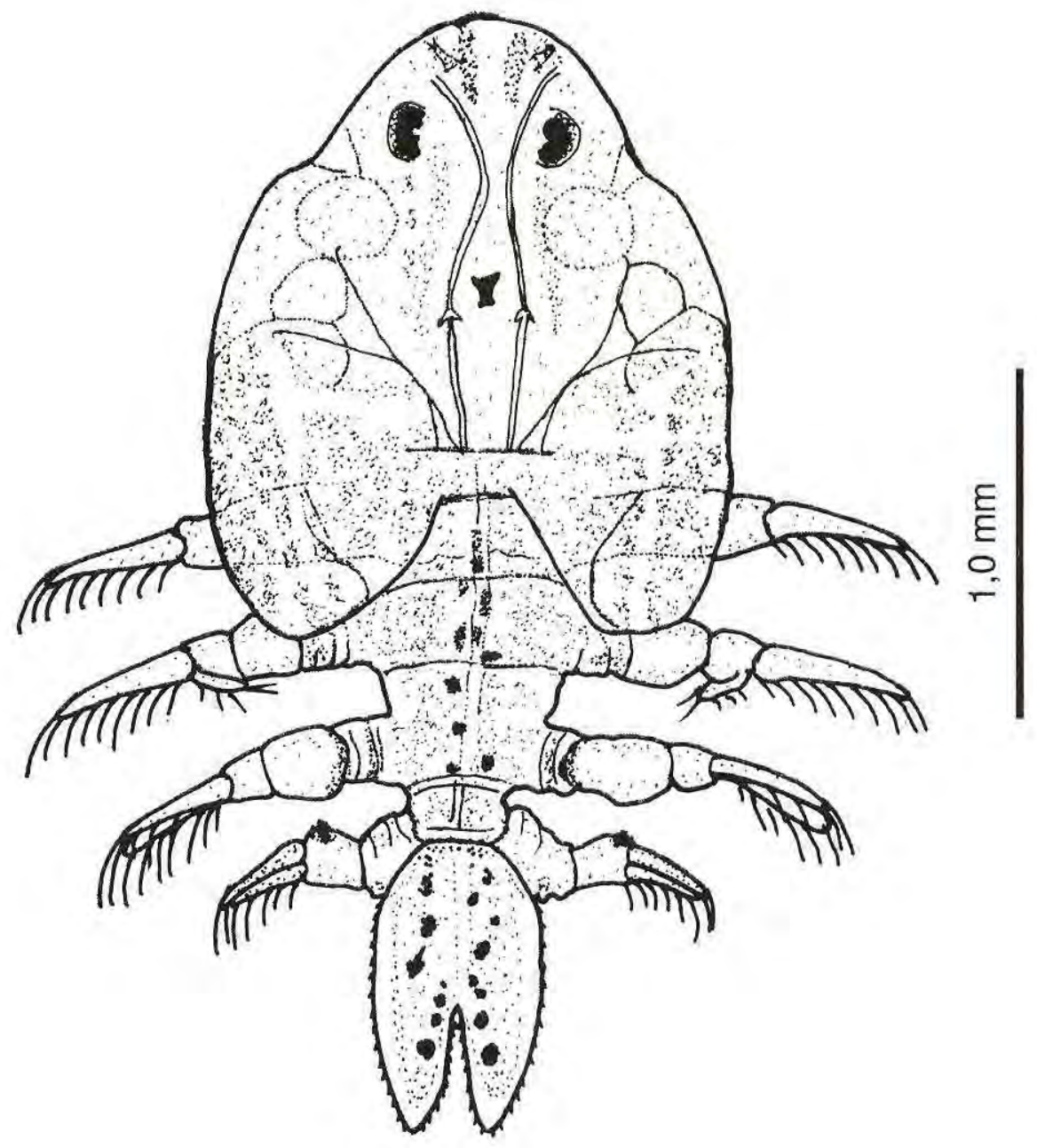

Figura 13. Argulus chicomendesi sp, n., macho, corpo em vista dorsal. 
externa é a menor as demais aumentam gradativamente de tamanho até a quarta.

Primeiro par de pernas (Fig. 14) com uma pequena seta plumosa apontando para a margem externa, um desenho em forma de círculo e duas faixas transversais paralelas formadas por tênues pigmentos castanhos no primeiro segmento. Segundo par de pernas (Fig. 15) com o primeiro segmento e o exopódito com espinhos na margem anterior e com um desenho de forma irregular no primeiro segmento formados por tênues pigmentos castanhos. Terceiro par de pernas (Fig. 16) com primeiro segmento e o exopódito com espinhos na margem anterior, segundo segmento com espinhos somente no quinto posterior. Simpóditos (primeiro e segundo segmentos) (Fig. 16) modificados e possuindo uma elevação em forma de xícara (estrutura copulatória acessória) na margem posterior. Quarto par de pernas (Fig. 17) com uma pequena seta próxima à sua inserção ao tórax; primeiro segmento com duas faixas paralelas transversais de pigmentos, lobo natatório (expansão do coxopódito) evidente $\mathrm{e}$ com margens arredondadas, ornadas com cinco setas plumosas e com forte pigmentação em toda sua extensão. Segundo segmento (Fig. 17) com duas faixas paralelas de pigmentos, margem posterior com três setas plumosas. Simpóditos (primeiro e segundo segmentos) (Fig. 16) modificados no ponto de oposição da elevação em forma de xícara (estrutura copulatória acessória) do terceiro par de pernas. Modificações do quarto par de pernas do macho inclui uma forte projeção anterior com uma abertura mediana, tendo o formato interior da letra "U". No terço distal de sua base uma área pigmentada que se eleva suavemente em direção distal com borda arredondada, toda sua base com setas plumosas direcionadas posteriormente (Fig. 16).

Etimologia: o nome específico é uma homenagem a Francisco Mendes, o grande líder popular amazônida, defensor dos povos da floresta. Deriva da junção dos dois nomes de como era conhecido: Chico Mendes: chicomendesi.

\section{DISCUSSÃO}

Das nove espécies do gênero Argulus citadas para o Brasil, quatro ocorrem na Amazônia brasileira: Argulus multicolor Stekhoven, 1937 que parasita Rhaphiodon vulpinus Agassiz, 1829; Pygocentrus nattereri (Kner, 1860); Colossoma macropomum; Cichla temensi (Humboldt, 1833) e, Satanoperca jurupari (Heckel, 1840); Argulus pestifer Ringuelet, 1948 que parasita Pseudoplatystoma tigrinum e $P$. fasciatum (Linnaeus, 1776); Argulus juparanaensis Lemos de Castro, 1950 que parasita Megalodoras sp. Eigenmann, 1925 e Pseudoplatystoma fasciatum além de Argulus amazonicus Malta \& Santos-Silva, 1986 parasita 


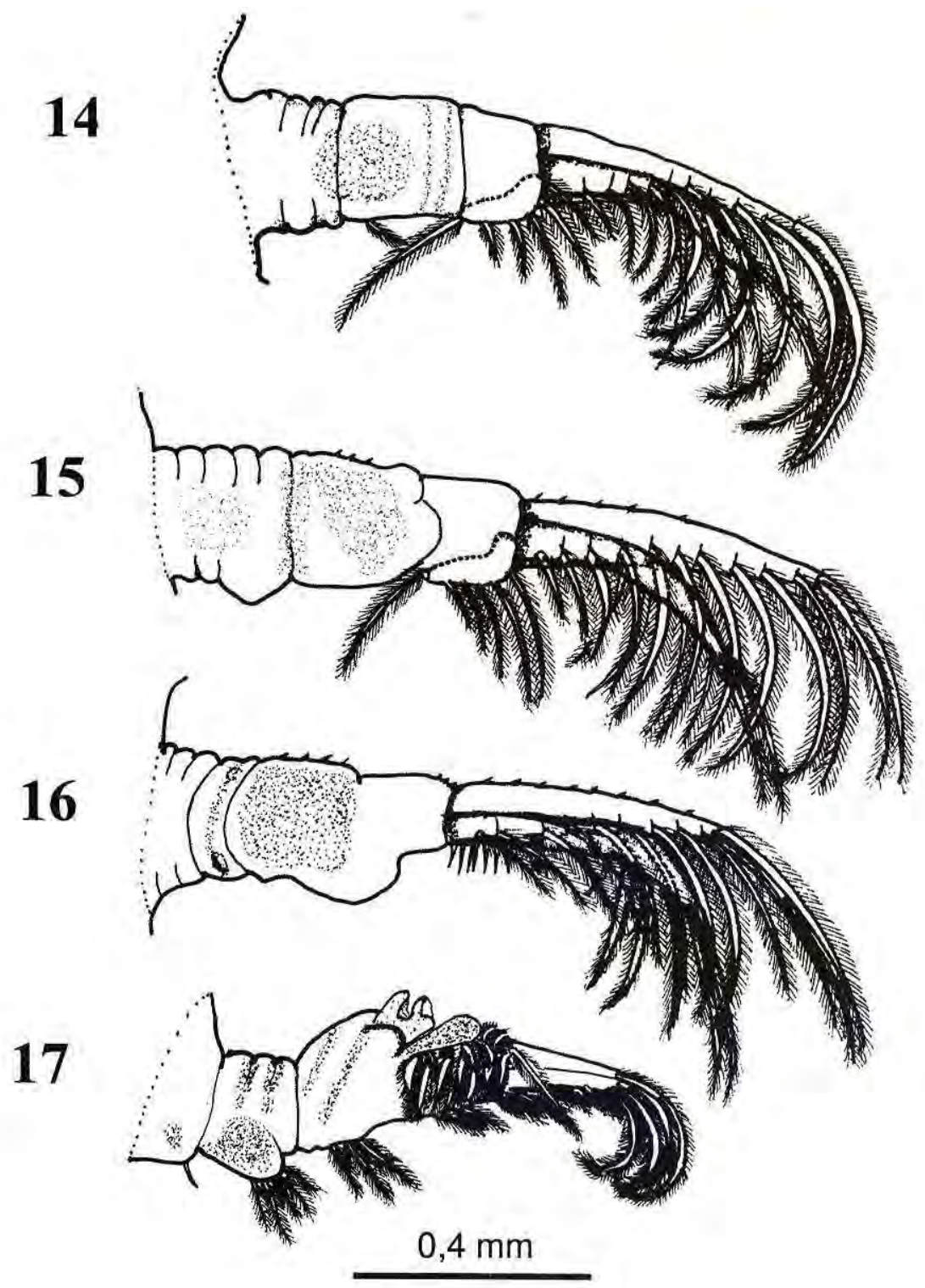

Figuras 14-17. Argulus chicomendesi sp. n., macho (vista dorsal): 14 - perna 1; 15 - perna $2 ; 16$ - perna $3 ; 17$ - perna 4 , 
de Cichla ocellaris Bloch \& Schneidert, 1801 e C. temensis (Malta, 1998), encontrado parasitando, também, Osteoglossum bicirrhosus (Vandelli, 1829) (observação do primeiro autor deste trabalho).

Apesar de ter em comum o hospedeiro (tambaqui, Colossoma macropomum) e o local de coleta, a fêmea de Argulus chicomendesi difere da de Argulus multicolor: por ser bem menor, menos da metade do tamanho; no formato das hastes quitinosas de sustentação; na cobertura do primeiro e segundo pares de pernas pelos lobos laterais da carapaça nos desenhos da carapaça, tórax, abdômen; no formato do abdômen; nas ornamentações das antênulas, antenas, maxilas e na distância entre as maxílulas.

O macho de Argulus chicomendesi difere de Argulus multicolor (descrito de apenas um exemplar): por ser menor; no formato nos desenhos da carapaça, tórax, abdômen; no formato da carapaça, do abdômen; nas ornamentações das antênulas, antenas, maxilas; na distância entre as maxílulas; em todo o sistema de modificações sexuais do terceiro e quarto pares de pernas.

Uma segunda espécie que tem alguma semelhança com $A$. chicomendesi é Argulus elongatus Heller, 1857 (descrito de apenas um exemplar fêmea). A nova espécie difere: por ser menor; nos desenhos e coloração dorsais da carapaça e do metassomo; por apresentar lobos laterais da carapaça (alae; asas, áreas posterolaterais) bem definidos arredondados e separados por largo sinus (seio posterior do pléon), na outra espécie ambos são ausentes; tamanho do abdômen menor; formato e sinus do abdômen diferentes; maxilas armadas com três dentes maxilares semelhantes (ausentes na segunda espécie); presença de flagelos nos dois primeiros pares de pernas (pereópodo, toracópodo), ausentes na outra espécie.

A combinação dos caracteres de Argulus chicomendesi aliados ao formato e composição dos desenhos dorsais da carapaça, metassomo e abdômen; presença de espinhos na margem externa do abdômen (pléon) tanto no macho quanto na fêmea; pernas com ornamentações, estruturas copulatórias acessórias e pigmentação típicas e ornamentação das maxílulas são características exclusivas desta espécie.

Argulus chicomendesi foi a primeira espécie que apresentou um alto índice de infestação em peixes cultivados na Amazônia. Em 1983, apresentou uma infestação maciça em Brycon cf. cephalus (Günther, 1869), na Estação de Aquacultura do Instituto Nacional de Pesquisas da Amazônia, Manaus, Estado do Amazonas. Em 1998, esta mesma espécie foi coletada parasitando o tambaqui (Colossoma macropomum), em uma Estação de Aquacultura no município de Itacoatiara, esta infestação era baixa, cerca de, dois a quatro branquiúros por hospedeiro.

\section{Bibliografia citada}

Bouvier, M. E. L. 1899. Les crustacés parasites du genre Dolops Audouin. Bulletin de la 
Société Philomathique (sèrie 8), 10(2/ 3):53-81.

Bouvier, M. E. L. 1899. Les crustacés parasites du genre Dolops Audouin. Bulletin de la Société Philomathique, (sèrie 9) $1(1): 12-40$.

Benz, G.W.; Otting, R.L.; Case, A.. 1995. Redescription of Argulus melanostictus (Branchiura: Argulidae), a parasite of California grunion (Leuresthes tenuis: Atherinidae), with notes regarding chemical control of $A$. melanostictus in a captive host population. Journal of Parasitology, 81(5):754-761.

Calman, W.T. 1912a. Dipteropeltis hirundo. Abstract Proceedings of Zoological Society of London, 34.

Calman, W.T. 1912b. On Dipteropeltis, a new genus of the crustacean order Branchiura. Proceedings of Zoological Society of London, 3:763-767.

Kabata, Z. 1970. Diseases of fishes book 1: Crustaceans and enemies of fishes. TFH, Jersey City, USA. 171p.

Kabata, Z. 1985. Parasites and diseases of fishes cultured in the tropics. Taylor \& Francis, London, UK. 318p.

Lemos de Castro, A. L. 1950. Contribuição ao conhecimento dos crustáceos argulídeos do Brasil. Descrição de duas novas espécies. Anais da Academia Brasileira de Ciências, 2(2):245-252.

Malta, J.C.O. 1981. Os crustáceos Branchiura e suas interrelações com os peixes do lago Janauacá, AM. Brasil (Crustacea: Argulidae). Tese de Mestrado, Instituto Nacional de Pesquisas da Amazônia(INPA) - Universidade do Amazonas, Manaus, Amazonas. 88p.

Malta, J.C.O. 1982a. Os argulídeos (Crustacea: Argulidae) da Amazônia Brasileira. Aspectos da ecologia de Dolops discoidalis Bouvier, 1899 e D. bidentata Bouvier, 1899. Acta Amazonica, 12(3):521-528.

Malta, J.C.O. 1982b. Os argulideos (Crustacea: Argulidae) da Amazônia Brasileira, 2. Aspectos da ecologia de Dolops geayi
Bouvier, 1899 e Argulus juparanaensis Lemos de Castro, 1950. Acta Amazonica, 12(4):701-705.

Malta, J.C.O. 1983. Os argulídeos (Crustacea: Argulidae) da Amazônia Brasileira, 4. Aspectos da ecologia de Argulus multicolor Schuurmans Stekhoven, 1937 e A. pestifer Ringuelet, 1948. Acta Amazonica, 13(2):489-496.

Malta, J.C.O., 1984. Os peixes de um lago de várzea da Amazônia Central (lago Janauacá, rio Solimões) e suas relações com os crustáceos ectoparasitas (Branchiura: Argulidae). Acta Amazonica, 14(3-4):355-372.

Malta, J.C.O. 1998. Maxillopoda - Branchiura. In: Yong, P. (Ed.). Catalogue of Crustacea of Brasil. Museu Nacional, Rio de Janeiro. p.67 - 74.

Malta, J.C.O.; Varella, A. 1983. Os argulídeos (Crustacea: Argulidae) da Amazônia Brasileira. Aspectos da ecologia de Dolops striata Bouvier, 1899 e D. carvalhoi Lemos de Castro, 1949. Acta Amazonica, 13(2):299-306.

Malta, J.C.O.; Santos-Silva, E.N. 1986. Argulus amazonicus n. sp., crustáceo parasita de peixes da Amazônia Brasileira (Crustacea: Argulidae). Amazoniana, 9(4): 485-492.

Ringuelet, R. 1943. Revision de los Argulideos Argentinos (Crustacea: Branchiura) com el catalogo de las espécies neotropicales. Revista del Museo de la Plata, 2(19):43100.

Rushton-Mellor, S.K. 1994a. The genus Argulus (Crustacea: Branchiura) in Africa: two new species, $A$. fryeri and $A$. gracilis, the previously undescribed male of a A. brachypeltis Fryer and the identity of the male described as A. amblopites Wilson. Systematic Parasitology, 28:23-31.

Rushton-Mellor, S.K. 1994b. The genus Argulus (Crustacea: Branchiura) in Africa: redescriptions of type-material collected by Cunnington during the Lake Tanganyika Expeditions in 1913, with notes on $A$. giganteus Lucas and $A$. arcassonensis Cuénot. Systematic Parasi- 
tology, 28:33-39.

Rushton-Mellor, S.K. 1994c. The genus Argulus (Crustacea: Branchiura) in Africa: identifications keys. Systematic Parasitology, 28:51-63.

Wilson, C.B. 1902. American parasitc copepods beloging to the family Argulidae, with a bibliography of the group and a systematic review of all known species. Proceedings of the United States National Museum, 25:635-742.

Yamaguti, S. 1963, Parasites Copepoda and Branchiura of fishes. John Wiley, New York, USA. 1104p.1 